\section{ENTRE PASSADO E PRESENTE: NARRATIVAS DE MULTICULTURALIDADE NA FRONTEIRA}

DOI: $10.5935 / 2177-6644.20170004$

\author{
BETWEEN PAST AND PRESENT: \\ NARRATIVES OF \\ MULTICULTURAL ON BORDER \\ ENTRE PASADO Y PRESENTE: \\ NARRATIVAS DE \\ MULTICULTURALISMO EN LA \\ FRONTERA
}

Thiago Reisdorfer*

\begin{abstract}
Resumo: Este texto tem por objetivo apresentar e historicizar os usos da ideia de multiculturalidade nas narrativas sobre Foz do Iguaçu e sua condição fronteiriça. Tais narrativas buscariam aliar "atrativos naturais" da região, com aquele que seria seu diferencial no "mercado de cidades": o ambiente multicultural que teria sido construído a partir da coexistência harmoniosa entre as dezenas de etnias e nacionalidades que ali habitam. Buscamos compreender como os embates entre elites tradicionais da cidade e tecnocratas vinculados a construção de Itaipu a partir de 1975, constituíram estes usos do passado para a construção de uma memória social de harmonia cultural no presente. Dessa forma, foi possível perceber a conformação de uma narrativa sobre o passado que partiu de embates entre grupos sociais distintos, e se colocou a serviço da promoção turística da cidade e da acomodação social entre os grupos dominantes por meio da propaganda da multiculturalidade e de uma suposta harmonia cultural.
\end{abstract}

Palavras Chave: Multiculturalidade. Memória. Cidade.

\begin{abstract}
The objective of this text is to present and to become historic uses of the idea multicultural on narratives about Foz do Iguaçu and its border condition. The objective of these narratives would be to connect regional "natural attractions" to its supposed differential on "urban markets": the multicultural environment that would has been built based on balanced coexistence among tens of ethnicities and nationalities living there. We've tried to understand how clashes between traditional elites and technocrats linked to Itaipu building since 1975 constituted these uses of the past to build a social memory of cultural harmony in present. In this way, it was possible to realize a conformation of a narrative about the past based on clashes among different social groups and it was utilized as city touristic promotion and social accommodation among dominant groups thought ads of multicultural and a supposed cultural harmony.
\end{abstract}

Keywords: Multicultural. Memory. City.

Resumen: Este artículo tiene como objetivo presentar y historicizar la utilización de la idea del multiculturalismo en las narativas de Foz de Iguazú y su condición fronteriza. Estos relatos buscan combinar "atracciones naturales" de la región, y lo que podría ser su ventaja en los "mercados de ciudades": el ambiente multicultural que habría sido construida sobre la coexistencia armoniosa entre los de decenas etnias y nacionalidades que viven allí. Buscamos entender cómo los conflictos entre las élites tradicionales de la ciudad y tecnócratas ligados a la construcción de Itaipú de 1975, construyeron estos usos del pasado para construir una memoria social de armonía cultural en el presente. Por lo tanto, fue posible ver la configuración de una narración sobre el pasado que dejó enfrentamientos entre diferentes grupos sociales, que se pone al servicio de la promoción turística de la ciudad y el compromiso social entre los grupos dominantes a través de la propaganda multicultural y una supuesta armonía cultural.

Palabras clave: Multiculturalismo. Memoria. Ciudad.

\footnotetext{
* Doutorando em História do Tempo Presente pela Universidade do Estado de Santa Catarina - UDESC. E-mail: thiagorhs@ hotmail.com
} 
A cidade de Foz do Iguaçu é comumente narrada a partir de suas características geográficas, sejam as modificadas pelo homem, como a barragem de Itaipu e seu lago, sejam as legadas pela natureza, as Cataratas do Iguaçu, sejam aquelas erigidas nas historicidades humanas, sua tríplice fronteira. A construção desse espaço como uma fronteira política, cultural e simbólica, a partir de embates ao longo de séculos, possibilitou um lugar privilegiado para o encontro, dialógico ou tenso, de povos e culturas. Dos usos políticos dessa possibilidade surge uma ideia generalizada nos meios sociais e acadêmicos de uma Foz do Iguaçu enquanto fronteira multicultural. Este processo é analisado aqui a partir da chegada de importantes grupos sociais, tanto populares quanto uma nova elite tecnocrata com a construção da barragem de Itaipu, principalmente a partir de 1975 com o início das obras na barragem.

Diversos são os agentes e espaços que alardeiam ou recorrem a essa ideia. Seja no campo acadêmico, na imprensa - escrita, televisionada ou virtual - ou nos meios estatais oficiais como a prefeitura municipal. Ao se debruçarem sobre a constituição étnica da cidade, atualizam o passado no presente. Incorporam ao presente um suposto passado "idílico" onde as etnias se respeitariam e viveriam em harmonia. Para a análise destas questões as ferramentas da História do Tempo Presente se fazem de particular utilidade e interesse. Observar e problematizar os usos e a presença do passado no presente tem sido base de sustentação desse campo historiográfico, bem como, de suas contribuições teóricas e metodológicas.

Para que possamos pensar sobre as formas como as temporalidades da cidade de Foz do Iguaçu tem sido utilizadas para construir sentidos sobre aquela historicidade, abordaremos como fontes para este texto, três sites. Para a sua seleção, optamos por um procedimento metodológico que busca replicar, pelo menos de maneira geral, formas e usos comuns para usuários da internet. Ao acessar o buscador Google inserimos o nome da cidade em busca de resultados. Assim, transformamos uma ferramenta cotidiana, em um ato construtor de fontes históricas, os cliques digitais se transformam em matéria prima do historiador. Ao fazermos esse movimento nos deparamos com o seguinte resultado: Em primeiro lugar apareceu o site da prefeitura de Foz do Iguaçu; em segundo a seção de turismo do site da Prefeitura de Foz do Iguaçu; em terceiro uma página de

\footnotetext{
${ }^{1}$ Disponível em: www.google.com.
} 
turismo sobre Foz do Iguaçu, chamada Visite Foz e, em quarto, a página sobre a cidade no site Wikipédia. ${ }^{2}$

Pesquisas históricas que se utilizam de fontes online e/ou digitais de diferentes formas, ainda carecem de problematização metodológica. Cada vez mais acessíveis, por exemplo, pela digitalização de acervos de fontes, pela utilização de meios digitais como o Skype para a construção de entrevistas, ou pela pesquisa em blogs, imprensa digital, ou sites oficiais, contam ainda com pouca discussão metodológica. ${ }^{3}$ Dessa forma, para a construção da presente análise, buscamos construir alguns critérios que possibilitassem uma padronização de resultados.

Em nosso caso, para a realização da pesquisa foi feito um esforço na busca de evitar vícios na ferramenta Google. Para tanto, utilizamos um computador e um navegador "em branco", ou seja, ainda não utilizado para pesquisas e sem vinculação a conta Google. Tal fato faz-se necessário, pois este buscador utiliza como forma de filtrar as informações, além da relevância dos termos, e publicidades pagas, o histórico de buscas da conta Google ao qual o computador, ou navegador, está vinculado. Desta forma, conseguimos o que seria um "resultado padrão" para primeiras buscas sobre a cidade. Para tanto, foram desconsideradas as "buscas patrocinadas", aqueles resultados que aparecem em primeiro e em destaque quando encontrados e são fruto de campanhas publicitárias pagas. Esse resultado pode ser diferente dependendo do histórico de buscas de cada usuário.

As três páginas da internet aqui analisadas, são bastante amplas e com objetivos que, assim como praticamente toda fonte histórica, foge do escopo da problemática do historiador. Para a realização das análises que aqui nos propomos foi necessário a realização de um recorte a respeito das áreas dos sites que seriam analisadas. Focamos em áreas que abordavam a história de Foz do Iguaçu, sua população, bem como, páginas iniciais que dentro do site tinham por função a apresentação da cidade ao visitante online. Assim, no caso do site da Prefeitura Municipal, ${ }^{4}$ mantido pelo poder público,

\footnotetext{
${ }^{2}$ Site da Prefeitura Municipal de Foz do Iguaçu: http://www.pmfi.pr.gov.br/. Acesso em: 09/05/2016. Site da Secretaria Municipal de Turismo de Foz do Iguaçu: http://www.pmfi.pr.gov.br/turismo/. Acesso em: 09/05/2016. Site Visite Foz: http://www.visitefoz.com.br/. Acesso em: 09/05/2016. Página sobre Foz do Iguaçu na Wikipédia: https://pt.wikipedia.org/wiki/Foz_do_Igua\%C3\%A7u. Acesso em: 09/05/2016.

${ }^{3}$ Em 2014 a revista Tempo e Argumento publicou um dossiê chamado "História e Internet". Nesse dossiê discutiu-se tanto as transformações na experiência a partir dos usos da internet, quanto possibilidades historiográficas que esse amplo e diverso meio pode apresentar.

${ }^{4}$ Disponível em: http://www.pmfi.pr.gov.br/. Acesso em: 09/05/2016.
} 
foram analisados os itens: "A Cidade", 5 "História da Cidade" $\mathrm{e}$ "Cronologia Histórica do Município". ${ }^{7}$ A página da Wikipédia sobre a cidade de Foz do Iguaçu ${ }^{8}$ teve seu texto analisado integralmente. Já a página "VisiteFoz", ${ }^{9}$ voltada para o turismo, teve analisada três itens: "Sobre a cidade", ${ }^{10}$ "Centenário de Foz do Iguaçu" ${ }^{11}$ e "Estudando em Foz do Iguaçu". ${ }^{12}$

Para a realização das análises, estruturamos o texto em dois momentos distintos. De início buscamos fazer um mapeamento das narrativas de multiculturalidade e harmonia cultural no presente da cidade de Foz do Iguaçu. Na sequência buscamos analisar o processo de construção, motivações e caminhos utilizados para a formação dessa memória oficial que significa o presente dessa cidade a partir da dupla ideia de belezas naturais e harmonia cultural. Essa construção narrativa ao ser realizada permitiu transformarmos em prática a já consolidada ideia de que a operação historiográfica passa pelo presente questionando o passado. Assim, de concepção teórica, buscamos transformar essa possibilidade em prática narrativa.

\section{Uma cidade de fronteiras: Foz do Iguaçu entre a fronteira e a multiculturalidade}

$\mathrm{Na}$ análise textual dos três sites pode-se perceber duas questões principais e que permeiam a todos. A primeira é a similitude dos textos. A segunda, a ausência de referenciais historiográficos para as afirmações ali contidas. Os textos presentes na Wikipédia e no site da prefeitura municipal são muito similares, em especial quando tratam da história do município e sobre as características da população. É inviável qualquer afirmação em relação a autoria dos textos, ou que permita apontar qual o texto original, tanto por não haver assinatura, quanto por não haver data de publicação. A única indicação de relação é a presença na página da Wikipédia de link para o site da prefeitura. Já a página VisiteFoz, contém um texto relativamente original em relação aos outros dois, mas utiliza marcos temporais e categorias de análises similares, em especial,

\footnotetext{
${ }^{5}$ Disponível em: http://www.pmfi.pr.gov.br/conteudo/?idMenu=1004. Acesso em 10/05/2016.

${ }^{6}$ Disponível em: http://www.pmfi.pr.gov.br/conteudo/?idMenu=1007. Acesso em 10/05/2016.

${ }^{7}$ Disponível em: http://www.pmfi.pr.gov.br/conteudo/?idMenu=1009. Acesso em 10/05/2016.

${ }^{8}$ Disponível em: https://pt.wikipedia.org/wiki/Foz_do_Igua\%C3\%A7u. Acesso em 10/05/2016.

${ }^{9}$ Disponível em: http://www.visitefoz.com.br/. Acesso em 10/05/2016.

${ }^{10}$ Disponível em: http://www.visitefoz.com.br/foz-do-iguacu/sobre-a-cidade/. Acesso em 10/05/2016.

${ }^{11}$ Disponível em: http://www.visitefoz.com.br/foz-do-iguacu/centenario-de-foz/. Acesso em 10/05/2016.

${ }^{12}$ Disponível em: http://www.visitefoz.com.br/foz-do-iguacu/estudando-em-foz/. Acesso em 10/05/2016.
} 
quanto a questão da multiculturalidade com destaque para a presença de um grande número de etnias presentes naquela localidade.

Mas o que dizem as três páginas a respeito da presença de diversas culturas e da fronteira? Comecemos pelo site da Prefeitura Municipal:

Foz do Iguaçu está localizada no extremo oeste do Paraná, na divisa do Brasil com o Paraguai e a Argentina. A cidade é centro turístico e econômico do oeste do Paraná e é um dos mais importantes destinos turísticos brasileiros. Com cerca de 260 mil habitantes, Foz do Iguaçu é caracterizada por sua diversidade cultural. São aproximadamente 80 nacionalidades, sendo que as mais representativas são oriundas do Líbano, China, Paraguai e Argentina. ${ }^{13}$

Esta é a fala de abertura da página da prefeitura que tem por objetivo apresentar a cidade a partir da perspectiva do poder público municipal. Nela é possível perceber algumas questões relevantes para a problemática levantada nesse momento do texto. De início é perceptível a forma como a sua localização é construída. Primeiro, sua posição geográfica em relação ao Paraná. Logo em seguida sua característica de cidade de fronteira é demarcada, apontando essa condição e, também, os países com os quais faz fronteira. Uma narrativa de localização geográfica não é algo natural. Ao demarcar sua condição fronteiriça logo na primeira frase de apresentação da cidade, possibilita perceber a dimensão que essa condição assume no discurso oficial daquela localidade. Na sequência chama a atenção a opção narrativa que se constrói para dar continuidade à apresentação da cidade. É o turismo, ${ }^{14}$ atividade econômica privilegiada por esse discurso que faz a conexão entre sua condição de fronteira e a descrição de sua população.

À fronteira e ao turismo soma-se a terceira característica daquela espacialidade: a diversidade cultural. Enfatiza-se uma grande quantidade de etnias, "aproximadamente 80 nacionalidades", e constrói-se um discurso de representatividade das principais nacionalidades ali presentes. Libaneses, chineses, paraguaios e argentinos se destacam. De maneira "irônica", os brasileiros não aparecem, sendo naturalizados na narrativa. Destaque-se que na forma como são narrados, não vemos grupos culturais, mas sim, nações representadas. Não árabes, latinos, orientais, etc., mas paraguaios e argentinos, libaneses e chineses.

\footnotetext{
${ }^{13}$ Disponível em: http://www.pmfi.pr.gov.br/conteudo/?idMenu=1004. Acesso em 10/05/2016.

${ }^{14}$ A respeito da diversidade cultural como característica explorada pelo turismo ver Klauck e Szekut (2012).
} 
Tal caracterização é relevante para a argumentação que buscamos tecer. Foz do Iguaçu se apresenta como uma cidade da diversidade, da multiculturalidade. Mais do que um espaço de encontro e contato entre culturas, vemos chamado a público a existência dessa diversidade, sem ênfase nos contatos culturais. Vejamos outra descrição sobre a diversidade étnica daquela cidade, ainda no site da prefeitura:

Foz do Iguaçu tem uma composição étnica muito variada e interessante, estimando-se hoje uma população de 263.508 habitantes.

A cidade abriga cerca de 80 das 192 nacionalidades existentes no mundo. Caminhando pelas ruas da cidade não é surpresa nenhuma deparar-se com japoneses, chineses, coreanos, franceses, bolivianos, chilenos, árabes, marroquinos, portugueses, indianos, ingleses, israelenses e tantas outras nacionalidades, sem contar ainda paraguaios e argentinos. Os diferentes grupos étnicos residentes na cidade fazem de Foz do Iguaçu uma das cidades mais cosmopolitas do Brasil. ${ }^{15}$

Nesse texto, apresentado na sequência do anterior, há um reforço na ideia de diversidade populacional. Novamente o que vemos aqui é uma ênfase na possibilidade de existência de tais grupos, pois "deparar-se" remete a uma perspectiva muito mais contemplativa do que interacionista. A diversidade, mais uma vez, aparece como um fim em si mesmo.

Mas em que medida essa narrativa é reproduzida em outros espaços? Dentre nossas fontes, podemos destacar na sequência a forma como a página da Wikipédia aborda essa questão. Antes, porém, gostaríamos de destacar a centralidade que esse portal de informações tem atingido na contemporaneidade. Substituindo ou, em regiões com menor acesso à internet, complementando as antigas Enciclopédias e outros meios físicos de pesquisa, este portal tem assumido importante dimensão na realização de pesquisas e trabalhos escolares. Seja através da cópia, resumo ou pesquisa de conteúdo essa é uma fonte formadora de percepções e pesquisas escolares. Influenciando, dessa forma, na formação cultural das novas gerações criadas em interação constante com os meios virtuais. De toda forma, vejamos como a página de Foz do Iguaçu, no item demografia, apresenta a população desse município:

Foz do Iguaçu é considerada um dos municípios mais multiculturais do Brasil, onde estão presentes mais de 72 grupos étnicos, provenientes de diversas partes do mundo, e dentre dos principais estão os italianos,

\footnotetext{
${ }^{15}$ Disponível em: http://www.pmfi.pr.gov.br/conteudo/?idMenu=1004. Acesso em 10/05/2016.
} 
alemães, hispânicos (argentinos e paraguaios), chineses ucranianos, japoneses. Destaca-se que está presente a segunda maior comunidade libanesa do Brasil. Em termos proporcionais, possui a maior comunidade islâmica do Brasil.

Devido a sua localização de fronteira com o Paraguai e a Argentina, Foz do Iguaçu apresenta uma grande circulação de mercadorias contrabandeadas, drogas e armas, o que gera diversos problemas sociais, principalmente a violência, fazendo com que a taxa de homicídios seja muito alta em proporção ao número de habitantes. O município lidera o ranking de homicídios entre adolescentes no país. ${ }^{16}$

A narrativa construída sobre a população possui duas dinâmicas distintas. Primeiro a ênfase na multiculturalidade que, ao evidenciar a ideia de que este seria um dos "municípios mais multiculturais do Brasil", é percebida como uma característica distintiva e positiva dessa cidade. Há, entretanto, distinções entre a narrativa a esse respeito presentes na página da Wikipédia e na página da Prefeitura Municipal. Primeiro o número de grupos étnicos ou etnias presentes na cidade. ${ }^{17}$ Em seguida temos uma mudança na narrativa construída a partir de países de origem, para a etnicidade ou suposto pertencimento cultural. Assim, de "oriundos" da China, Argentina e Paraguai, passamos para chineses e hispânicos - argentinos e paraguaios. Se em 1982, Wachowicz (1982, p. 28) afirmava que enquanto colônia militar no século XIX aquela localidade estava "de costas para o Brasil", e de frente para Argentina e Paraguai, vemos aqui uma inversão. O discurso da Wikipédia e da Prefeitura Municipal coloca Foz do Iguaçu de costas para Argentina e Paraguai e voltada para o Brasil, a Europa, o Oriente e seu passado colonial.

É importante apontar a utilização de um referencial colonial para a caracterização da população proveniente de Argentina e Paraguai. Esta narrativa permite evidenciar nossa argumentação teórica anterior. O presente e as narrativas construídas a seu respeito não se produzem num vazio temporal. O sujeito que narra o presente, mesmo que oculto no anonimato da Wikipédia, é um sujeito histórico, seu discurso é permeado por espaços de experiências (KOSELLECK, 2012), e constrói significados inscrevendo sentidos sobre o objeto narrado. Ao atualizar a colonização espanhola como característica comum de argentinos e paraguaios, apaga uma historicidade de resistência, de forte presença

\footnotetext{
${ }^{16}$ Disponível em: https://pt.wikipedia.org/wiki/Foz_do_Igua\%C3\%A7u. Acesso em: 11/05/2016.

${ }^{17} \mathrm{O}$ surgimento da Universidade Federal da Integração Latino-Americana - Unila em 2010, juntamente com outras dinâmicas de imigração internacional contemporâneas, possibilitam um incremento no número de nacionalidades - tomadas por esses sites como etnias - na cidade, com o exemplo mais marcante pela importância em âmbito nacional, dos haitianos.
} 
populacional de origem indígena, em especial no Paraguai - cujas línguas oficiais são o espanhol e o guarani - constrói uma aproximação idealizada e politicamente segregadora com a Europa, ao mesmo tempo em que os distancia da América Latina.

Deixemos em suspenso por algumas linhas a narrativa sobre a fronteira. Vejamos agora como nossa terceira fonte trata da questão da multiculturalidade:

Foz do Iguaçu é reconhecida internacionalmente pela natureza exuberante das Cataratas do Iguaçu, pela construção monumental da Usina Hidrelétrica de Itaipu, e pelas famosas oportunidades de compras em Ciudad del Este. Uma cidade tri-nacional, que une Brasil, Paraguai e Argentina, e multicultural, caracterizada pelas diferentes culturas dos visitantes que compartilham espaços a cada semana. Uma cidade que desperta o interesse, sempre que citada. ${ }^{18}$

O site VisiteFoz é uma página online dedicada a informações para turistas. Organização privada, sem autoria identificada na página, possui um rol de informações para auxiliar possíveis visitantes daquela cidade. Voltado para os diferentes públicos, admiradores das Cataratas do Iguaçu, visitantes da Itaipu, ou compradores ocasionais em Ciudad del Este, constrói uma imagem de tranquilidade, harmonia e beleza para a cidade ou, ao menos, para o potencial turista. Se na página da Prefeitura Municipal a presença de várias etnias é narrada a partir da ideia de diversidade, assim como no caso da página da Wikipédia, aqui a ideia de multiculturalidade é explicitada. Enquanto naquela página a multiculturalidade era comemorada como uma distinção de Foz do Iguaçu em relação a outros espaços, aqui é nomeada como um dos elementos que despertariam o interesse do turista distinguindo-a daqueles destinos que possuem "apenas" belezas naturais. A diversidade cultural aparece como um diferencial competitivo nesse mercado de destinos turísticos. Associada à multiculturalidade vem a sua característica fronteiriça. No âmbito do turismo tal perspectiva pode ser fundamental pois, uma parcela significativa dos turistas toma Foz do Iguaçu também como ponto de passagem em direção a Ciudad del Este para compras. ${ }^{19}$

A presença da fronteira na narrativa sobre a cidade já havia sido percebida quando da fala trazida pelo site da Prefeitura Municipal. Se lá, aparece como um marcador geográfico privilegiado, lembrado como referência para a localização da cidade, em outros momentos das narrativas construídas pelas fontes, essa ideia muda. No

\footnotetext{
${ }^{18}$ Disponível em: http://www.visitefoz.com.br/foz-do-iguacu/sobre-a-cidade/. Acesso em: 10/04/2017.

${ }^{19}$ Uma importante discussão a esse respeito pode ser encontrada em Souza (2009).
} 
caso do site VisiteFoz, a fronteira aparece primeiro como espaço de passagem, de estratégia (CERTEAU, 2014) - no caso dos sacoleiros - ou tática - no caso de compradores ocasionais - em que relações comerciais em ambos os lados permitem ganhos, definitivos ou momentâneos (SOUZA, 2009). Mas ela aparece também a partir de outra característica: a violência. ${ }^{20}$ Em um espaço em seu site denominado "Perguntas Frequentes" ${ }^{21}$ há a seguinte fala:

Assim como a maioria das cidades turísticas que se destacam no Brasil, o turismo em Foz do Iguaçu não costuma ser afetado por problemas de segurança ao se seguir o bom senso habitual de segurança. A cidade está localizada numa tríplice fronteira e tem tentando combater os problemas de segurança que historicamente afetam a região. ${ }^{22}$

Como visto acima, a página da Wikipédia constrói uma narrativa no mesmo sentido. Temos aqui uma distinção entre o site da Prefeitura Municipal e os demais. Enquanto a Prefeitura Municipal se limita a utilizar a fronteira como marco, positivandoa, pois a utiliza como elemento para a localização da cidade, os outros dois sites abordam a fronteira aproximando-a de uma narrativa de violência. Se distanciando da percepção de "harmonia" e "compartilhamento" da cidade, constroem a fronteira como a origem, causa e motivador da violência. Outros fatores, como, por exemplo, a desigualdade social, não são elencados, deixando à fronteira, enquanto linha de contato e, ao mesmo tempo, divisão, a responsabilidade por essa violência. Tal fato fica especialmente evidente no caso da página da Wikipédia. Já em VisiteFoz, constrói-se um corredor de "bom senso" onde o turista pode transitar sem ser atingido pelos prejuízos trazidos pela violência fronteiriça. Assim, ao turista, consumidor e/ou visitante, é possível aproveitar apenas o "lado bom" da experiência. Há nas narrativas uma mudança entre a fronteira que é espaço de oportunidade para táticas e estratégias, para uma fronteira causadora de violência. O sentido desse espaço é deslocado, mas esse deslocamento atinge apenas as vivências dos citadinos, o visitante pode aproveitar e, contanto que use "bom senso", estabelecer suas relações de apreciação das oportunidades da fronteira de maneira tranquila.

\footnotetext{
${ }^{20}$ Os textos de Souza (2009), Gonzalez (2009) e Catta (2003 e 2009) abordam sob diferentes perspectivas essa questão.

${ }_{21}^{21}$ Disponível em: http://www.visitefoz.com.br/informacoes-turisticas/faq-turistas/. Acesso em: 11/05/2016.

${ }^{22}$ Idem.
} 
O que temos percebido por meio da leitura dessas fontes, é a construção de uma narrativa sobre o presente daquela cidade. A existência de um grande número de etnias e culturas nesse espaço é utilizada para a construção de uma identidade de cidade multicultural. Entretanto, o presente não é uma temporalidade solta no tempo. Sua representação permite perceber construções históricas que possibilitam tais narrativas sobre esse tempo. Se este é um tempo fluído e dinâmico é formado, como afirma Koselleck (2012), no tensionamento entre espaços de experiências e horizontes de expectativas. Assim, as leituras sobre o presente carregam em si, um conjunto de expectativas sobre o futuro - nas fontes utilizadas o turismo é central -, mas também um conjunto de temporalidades que formam o espaço de experiências do objeto em questão - a ativação de um passado/presente multicultural.

Para a consecução de nosso objetivo faz-se necessário a construção de um movimento analítico que pense como as fontes aqui trabalhadas, enquanto conformadoras de um discurso oficial, utilizam-se de representações do passado para legitimar, ou evidenciar, uma suposta vocação multicultural de Foz do Iguaçu que é expressada, por exemplo, na evidenciação da existência de "aproximadamente 80" etnias na cidade. As três páginas analisadas dispõem de sessão dedicada a narrar a história de Foz do Iguaçu. Em todas, a narrativa é a de uma cidade em formação. Todo o passado é colocado à disposição do processo de formação da cidade do presente. Uma perspectiva teleológica atravessa essas análises. Com diferentes começos, a história é submetida à formação da cidade. Essa perspectiva apaga ou, ao menos, invisibiliza a historicidade daquela região. A única referência a uma historicidade pregressa à colonização oficial aparece a partir de relatos arqueológicos:

Pesquisas arqueológicas realizadas pela Universidade Federal do Paraná no espaço brasileiro do reservatório de Itaipu, antes de sua formação, situaram em 6.000 a.C. os vestígios da mais remota presença humana na região; vários grupos humanos sucederam-se ao longo dos séculos. Os últimos que precederam os europeus (espanhóis e portugueses) foram os índios. ${ }^{23}$

Sessenta séculos de história são minimizados a "vestígios" da presença humana naquele espaço. Além disso, cria-se uma fronteira temporal - num discurso que, como vimos anteriormente já é marcado por fronteiras geográficas - onde indígenas e europeus

\footnotetext{
${ }^{23}$ Disponível em: http://www.pmfi.pr.gov.br/conteudo/?idMenu=1007. Acesso em: 10/05/2016.
} 
se precedem. Mais uma vez o contato entre culturas é submetido a lógica da mera presença das mesmas. Novamente, frisa-se a existência da diferença, nunca o contato dialógico ou conflituoso, entre elas. Assim como nas narrativas sobre a presença de etnias ou nacionalidades, constrói-se uma separação entre as mesmas, enfatizando sua coexistência, nunca suas relações.

Se a história do espaço, enquanto história da presença humana e suas relações com determinada espacialidade, é deixada de lado por essa narrativa, a mesma se foca na construção da cidade. Assim, o discurso fundacional traça um caminho direto entre os primeiros habitantes, a fundação da Colônia Militar e a cidade de Foz do Iguaçu no presente. Esta última aparece como herdeira de uma história com um só sentido, sua formação.

Em 1881, Foz do Iguaçu recebeu seus dois primeiros habitantes, o brasileiro Pedro Martins da Silva e o espanhol Manuel Gonzáles. Pouco depois chegaram os irmãos Goycochéa, que começaram a explorar a erva-mate. Oito anos após, foi fundada a colônia militar na fronteira marco do início da ocupação efetiva do lugar por brasileiros e do que viria a ser o município de Foz do Iguaçu. ${ }^{24}$

Esta citação presente no item com o significativo nome de "História da Cidade", 25 possui diferentes elementos para pensar a argumentação que viemos apresentando. Primeiro, o anacronismo de colocar os supostos habitantes de 1881 como habitantes de Foz do Iguaçu. A suposta chegada destes dois homens aquele espaço já seria uma chegada a Foz do Iguaçu. Agrega-se a esse elemento, a grafia utilizada. Em primeiro lugar, em 1881 essa região permanecia sem nome, sendo localizada dentro do município de Guarapuava. Em segundo, a grafia do século XIX para Iguaçu era Iguassú, ${ }^{26}$ ou Iguassu. Entretanto, a Prefeitura Municipal, adota a grafia contemporânea sobre o passado. Outra significativa questão levantada por esse excerto é, novamente, a ênfase na presença de diferentes nacionalidades naquele espaço.

A fonte em questão afirma a migração em 1881 de dois homens para o espaço que seria Foz do Iguaçu. Tal momento é tomado como marco inicial da ocupação dessa região. Esse evento não pode ser confirmado por fontes em nenhuma das produções

\footnotetext{
${ }^{24}$ Idem.

${ }^{25} \mathrm{O}$ texto se repete na página sobre a cidade de Foz do Iguaçu na Wikipédia.

${ }^{26}$ Sobre a nomenclatura e história da fundação da colônia militar ver Myskiw (2009) que em sua tese de doutorado apresenta vasto conjunto de fontes de viajantes e fundadores oficiais da Colônia Militar, onde, através de documentos de época é possível perceber a grafia utilizada.
} 
historiográficas analisadas para esse trabalho. A primeira referência a esses sujeitos, entre a bibliografia analisada, aparece em Wachowicz: "Os mais antigos moradores da região da foz do rio Iguaçu, teriam sido o brasileiro Pedro Martins da Silva e o espanhol Manoel Gonzalez, que ali se estabeleceram em 1881" (WACHOWICZ, 1982, p. 21). Nenhuma fonte é apresentada para corroborar tal afirmação. Entretanto, em que pese a gravidade dessa ausência, nos interessa aqui as nacionalidades elencadas dos sujeitos. $\mathrm{O}$ "mito de origem" ${ }^{27}$ da escrita teleológica da história da cidade é construído sobre a presença de duas nacionalidades distintas. Desde seu marco de origem a história da cidade é marcada pela ideia de compartilhamento deste espaço por diferentes nacionalidades. Essa é uma narrativa poderosa, mesmo quando não evidenciada, em busca da construção de uma identidade multicultural para Foz do Iguaçu. Vemos aqui um movimento de uso do passado em busca da produção dessa identidade. O presente constrói e utiliza-se de um determinado espaço de experiências para legitimar sua identidade.

\section{Disputas pela memória e interculturalidade}

O que temos visto neste trabalho é um processo de construção e problematização de memórias, que seriam ou se projetam coletivas, para e sobre a cidade de Foz do Iguaçu. Resta-nos tentar construir uma explicação para esse processo histórico. Esta tentativa não é nova. Souza (2009) possui uma interessante e importante discussão sobre o processo de construção de uma memória social para a cidade. Outro texto que caminha nesse sentido é o já abordado trabalho de Klauck e Szekut (2012) que aborda a questão da memória a partir da problemática do patrimônio cultural da cidade. Esses trabalhos apresentam uma explicação calcada na ideia de turistificação da memória e da identidade social de Foz do Iguaçu.

Se concordamos que essa é uma dimensão essencial para pensar as questões aqui colocadas, como ficou evidenciado no início deste artigo, entendemos também que o processo de constituição da memória social (POLLACK, 1992) de Foz do Iguaçu tem dimensões históricas que precisam ser localizadas com maior precisão. A importância do turismo no presente não pode servir de chave colonizatória do passado, sendo utilizada

\footnotetext{
${ }^{27}$ Souza (2009) em subtítulo com o nome de "O Mito das Origens" aponta que memorialistas da cidade chegam a apontar a presença do espanhol Núnez Cabeza de Vaca por volta de 1542 como o início da história do município.
} 
como única explicação para as construções sociais. Pistas importantes podem ser encontradas no papel da Itaipu e das disputas entre as elites sociais da década de 1970 para a construção dessa memória. Assim, objetivamos complexificar essa problemática. Mas, antes, vejamos como esses textos constroem suas explicações.

A obra de Souza aborda e problematiza memórias de Foz do Iguaçu a partir dos grupos, ou classes sociais, tradicionalmente excluídos da memória e de seu processo de construção. Com esse objetivo, a autora, ocupa-se em analisar as formas como foram construídas as bases para uma memória citadina ancorada na dimensão do turismo. Utilizando como uma das fontes principais, especialmente no segundo capítulo, produções memorialísticas publicadas em especial a partir da década de 1970, mapeia as dimensões de conflitos e tensões que seriam constituintes do processo de construção da memória oficial de Foz do Iguaçu, bem como, apresenta os elementos importantes da mesma. Assim, a narrativa produzida, que ainda constitui a memória oficial da cidade, como vimos no início deste texto, não pode ser entendida sem antes compreendermos o que a autora apresenta como tensões que teriam marcado esse processo:

No início dos anos de 1980, havia, em Foz do Iguaçu, uma significativa tensão entre alguns grupos locais e os grupos responsáveis pela construção e a instalação da usina de Itaipu. Por parte dos grupos que historicamente prevaleciam na cidade, havia uma preocupação em defender sua posição de comando local, diante dos tecnocratas investidos de grande poder pelo governo federal. Tratava-se, naquele momento, de criar, para a cidade, uma identidade para se contrapor ao impacto da instalação da usina hidrelétrica. As elites locais iniciaram uma campanha em defesa de Foz do Iguaçu como cidade turística, que começou na década de 1980 e se estendeu pela década de 1990 (SOUZA, 2009, p. 80-81).

Focada na construção de uma narrativa que buscava demonstrar que a formação da cidade de Foz do Iguaçu estava intimamente ligada às suas belezas naturais, essa memória teria se constituído dentro de um jogo de interesses entre as elites tradicionais da cidade - como a família Schimelpfeng ${ }^{28}$ - e a elite formada pelos "tecnocratas" de Itaipu. Tal debate possuía uma multiplicidade de dimensões e buscava atuar em diferentes camadas do poder estatal circundante a Foz do Iguaçu. Colocada no centro

\footnotetext{
${ }^{28}$ Jorge Schimelpfeng foi o primeiro prefeito de Foz do Iguaçu em 1914. Sua família ocupa papel de destaque entre as elites tradicionais da cidade. Sua filha, Ottília Schimelpfeng, escreveu na década de 1970 um conjunto de textos memorialísticos que buscou colocar no turismo a centralidade do desenvolvimento da cidade ao longo do tempo.
} 
dos debates e interesses nacionais, a cidade poderia ser alvo privilegiado de políticas em âmbito estadual e federal. O fluxo de recursos, materiais e humanos, direcionados a Itaipu penderiam a balança de poder em direção à Binacional. Assim, o passado, ou melhor, as narrativas de passado, poderiam ser uma arma eficaz na luta pelo controle simbólico, econômico e político da cidade. No âmbito do econômico a busca por recursos nas esferas federais exigia uma narrativa de centralidade do turismo no e para o desenvolvimento da cidade (SOUZA, 2009, p. 79).

Essa memória de cidade turística não encontra respaldo na organicidade do processo de constituição de Foz do Iguaçu. Diversos historiadores ao discutir a região, tais como: Wachowicz (ano), Myskiw (2009) e Freitag (2007), apontam que a economia da região dependeu, pelo menos até a década de 1970, fortemente da extração de madeira e erva mate. Se já em meados do século XX hotéis foram construídos para explorar o turismo às Cataratas do Iguaçu, essa foi uma atividade econômica secundária, pelo menos até o último quarto do século passado. Assim, o que vemos é aquilo a que já nos referimos como uma colonização do passado pelo presente. Ou seja, o presente marcado pelo turismo e pelas disputas políticas entre tecnocratas e elites tradicionais, determina a apropriação do passado pelo último grupo a partir dessa ótica. Na mesma linha segue Souza:

Em certa medida, nestes relatos, a origem da cidade foi vinculada ao início do turismo, como se nesta atividade se explicasse a razão de criação e existência daquela. $\mathrm{O}$ mito do pioneiro articula-se à outra construção igualmente mítica da gente da terra, na perspectiva de estabelecer uma forte identificação entre o pioneiro e a cidade, de modo a não mais poder distingui-los. Assim, o que era interesse de um grupo passava a ser a vocação da cidade. Isso valoriza, ainda mais, o papel de seus fundadores, uma vez que estes eram identificados como os precursores do turismo, na cidade. Para explicitar o valor desta gente da terra, as narrativas feitas por Ottília [Schimelpfeng] procuravam identificar a região da Foz do Iguaçu como um espaço vazio, em termos culturais e populacionais, preenchido apenas por uma natureza exuberante, que, justamente por isso, merecia ser transformado [...] (SOUZA, 2009, p. 105).

O pioneiro, abordado por Souza, é utilizado como sinônimo de fundador da cidade, ou de dimensões da cidade, e localizado por Schimelpfeng nas pessoas que criaram estruturas voltadas para o turismo. Para a construção dessa narrativa, Souza identifica a necessidade de dois elementos principais. Primeiro, o discurso da natureza 
exuberante que atrai pessoas desde os primórdios da exploração da região remetendo, em alguns casos, à Cabeza de Vaca. ${ }^{29}$ Essa exuberância seria o motor da colonização e da vinda da população para o local. O segundo elemento é que para que este discurso tenha efeito, foi necessário a criação de uma narrativa de vazio populacional preenchido pelos atraídos pela natureza.

Souza ao discutir com a historiografia da cidade apenas como bibliografia para a realização de debates, passa ao largo do fato de que essa historiografia é elemento constituinte das memórias locais. No caso de Wachowicz, como vimos nas referências dos sites oficiais da cidade à presença de um espanhol e um brasileiro na região ainda no século XIX, sua obra é utilizada - mesmo que apenas como pano de fundo sem referência expressa - para fundamentar e criar academicamente a memória oficial da cidade. Assim, percebe-se nas disputas no município um jogo que envolve a historiografia local em embates que legitimam ou, em determinados momentos, deslegitimam essa memória oficial. Se as "elites tradicionais", como nomeia Souza, utilizam-se de memorialistas para abordar e construir sua versão voltada para seus interesses na área do turismo, os "tecnocratas" de Itaipu lançarão mão de historiadores contratados para construir uma versão alinhada aos seus interesses imediatos de harmonia social. ${ }^{30}$ Essa narrativa poderá ser utilizada tanto no embate com as elites tradicionais da cidade, quanto na tentativa de pacificação regional demandada pelos constantes tensionamentos causados pela obra de Itaipu. Com objetivos e lugares de partida distintos, constroem narrativas semelhantes.

O texto de Klauck e Szekut parte de uma premissa semelhante a nossa. Os autores busca compreender, através de um objeto diferente - o patrimônio cultural - como se formou um discurso de diversidade populacional em Foz do Iguaçu. Para isso utilizam de dois conjuntos de fontes: textos bibliográficos sobre a cidade, sites oficiais da municipalidade e reportagens da imprensa local. Ao discutirem a apresentação por parte da prefeitura municipal de uma citação de um dos memorialistas da Colônia Militar em que são apresentados os números de moradores e suas nacionalidades, avaliam que:

\footnotetext{
${ }^{29}$ Explorador espanhol que em viagem de exploração chegou a região por volta de 1542 .

${ }^{30}$ Centrada na ideia da construção de uma história da região oeste do Paraná o texto de Wachowicz “Obrageros, Mensus e Colonos", toma Foz do Iguaçu, a formação política-territorial dominante daquela região ao longo da primeira metade do século XX, como ponto de partida e centralidade histórica em sua análise. Outro elemento necessário para compreendermos a obra e sua importância na construção dos discursos oficiais está no fato de que esta foi financiada com recursos da Itaipu. Elaborada ainda durante o processo de construção da Usina, tem, por parte da empresa binacional, o objetivo de abordar a história da região a partir da ótica da integração, da harmonia social e da ausência de conflitos.
} 
A ênfase ao registro dos sujeitos encontrados reforça a conjectura de que se quer estabelecer ou mesmo fortalecer, que desde as origens primórdios da formação da cidade, um cenário de integração. Cabe destacar, que essa narrativa destoa do movimento de nacionalização dos espaços de fronteira, pois comumente essa região tornava invisível ou procurava controlar a presença de estrangeiros a partir dos aparatos do estado [...]. Essas assertivas indicam que o pano de fundo das narrativas e de seus agentes, está na concepção de integração que se quer passar através de representações marcadas pelos discursos e pelo poder simbólico que carregam (Grifos do autor) (SZEKUT e GLAUCK, 2012, p. 165-166).

As análises dos autores vão ao encontro de entender que os discursos de harmonia e multiculturalidade presentes na cidade buscariam embasar uma identidade marcada pela integração entre as culturas ali presentes. Para tanto o poder local se valeria da ênfase na visibilização da presença de uma expressiva quantidade de etnias e nacionalidades, demarcando, dessa forma, a ideia de integração e harmonia cultural. Essa demarcação teria um sentido histórico e político de construção de uma identidade construtora de diferenças e fronteiras em relação a outras cidades:

Estes agentes ao naturalizarem os discursos de que há harmonia entre as diversidades populacionais e que isso é um ponto positivo da cidade, marcam fronteiras em relação a outros espaços urbanos. Contudo, ao enquadrarem a memória coletiva, associada aos ciclos migratórios que definiram essa formação multicultural, escondem conflitos e disputas entre os agentes envolvidos nesse processo. Assim, definir e reconhecer intencionalmente a diversidade populacional como patrimônio cultural, no caso de Foz do Iguaçu, nos leva a considerar as operações de fixar silêncios e esquecimentos [...]. Mesmo assim, por fim, se torna inegável que as marcas da diversidade populacional, sejam signos capazes de mostrar a cidade como um palco multicultural (SZEKUT; KLAUCK, 2012, p. 174-175).

Se o discurso sobre a cidade posiciona as relações culturais como integradoras, os autores percebem que essa narrativa constrói, ou pelo menos contribui para construir, fronteiras simbólicas nas relações entre Foz do Iguaçu e outras cidades. Se levarmos em consideração que esse discurso é promovido, entre outros, por agentes do mercado de turismo, podemos avançar na análise e inferir que essa é uma ferramenta de disputa de mercado e sentidos, que extrapola o campo do simbólico, emergindo no campo econômico como disputa comercial. Assim, na busca de clientes, turistas, a harmonia cultural existente na cidade poderia ser um diferencial perante outros destinos. Ao 
mesmo tempo essa diferença poderia ser fator de atração de investimentos privados e públicos. Recursos para a promoção e preservação da diversidade como patrimônio cultural poderiam ser buscados nas instâncias estatais.

A denúncia dos usos político e econômico é acompanhada pelo reconhecimento da efetiva presença de uma ampla diversidade étnica e nacional na cidade. Este apontamento deve ser feito aqui também. Afinal, a ênfase que damos a problematização de discursos e narrativas promotoras de uma ideia de diversidade e harmonia cultural em Foz do Iguaçu não deve ser confundida com o não reconhecimento do fato de que, efetivamente, naquela cidade está presente uma pluralidade cultural expressiva. O que buscamos evidenciar são os usos políticos dessa pluralidade. Usos que ressaltam a convivência, não as trocas, tensões e diálogos; ressaltam a multiculturalidade e não a construção de possibilidades interculturais como abordado por Canclini (2009, p. 17).

No texto dos autores em tela, aparece de relance outra possibilidade de explicação, qual seja, a de que essa memória da diversidade teria surgido dentro dos embates existentes a partir da presença da Itaipu e, consequentemente, o surgimento de uma nova elite na cidade. Nosso intento ao apresentarmos esses dois textos, suas análises sobre a memória oficial da cidade e seu processo de construção, não é contrapormos as análises, mas sim, percebermos como tem sido abordada essa questão na academia e, a partir disso, apresentar colaborações ao debate. Nosso argumento, após a exposição da construção de uma memória oficial para a cidade de Foz do Iguaçu por meio da análise das fontes e da discussão com Souza e Klauck \& Szekut é que encontramos naquela cidade duas memórias oficiais em diálogo: para os memorialistas a serviço da elite local promotora do turismo, as Cataratas são o elo de ligação que une a história de Foz do Iguaçu; para Wachowicz, escrevendo em diálogo com os interesses de Itaipu, é a fronteira e sua característica de harmonia social. Interessante perceber como as duas interpretações acabam se fundindo e sendo utilizadas uma pela outra. Esta busca transforma a suposta harmonia social em multiculturalidade, agregando esta característica às atrações turísticas para a cidade ao lado das Cataratas do Iguaçu, da Itaipu e das compras no Paraguai. 


\section{Considerações finais}

A colaboração que buscamos trazer aqui é a compreensão de que o processo de construção da memória e da narrativa oficial de Foz do Iguaçu é bastante complexa e, certamente, não é ocasionado por apenas um fator. Se, no tempo presente, o turismo é a chave dominante para a compreensão dos usos da memória da cidade, sua formação possui elementos diversos e que se movem ao longo do tempo. Faz-se necessário retomar, mesmo que rapidamente, esse processo e nossa argumentação.

Primeiramente gostaríamos de apontar que quando tratamos aqui da memória oficial não estamos buscando apresentá-la de forma totalizadora e homogeneizadora. Todo grupo social, ou grupos sociais, possui um conjunto de memórias que não são monolíticas. No interior de qualquer grupo social disputas e tensões subjetivas e/ou materiais colocam em movimento jogos de disputas pela sua memória social e identidade. Em determinados casos setores hegemônicos podem conseguir atingir um nível de controle sobre o grupo que permita que o mesmo inscreva sua narrativa de memória como "a verdadeira", ou como a única legítima. No caso de uma cidade, esse poder inscritor pode vir de diferentes lugares, de setores dominantes da economia, da política, da cultura daquele espaço. Em nosso objeto, vemos uma construção simbiótica entre o poder público municipal, cuja manifestação foi trabalhada a partir do site da prefeitura municipal, e grupos dominantes da economia ligados ao setor de turismo da cidade, cuja construção narrativa foi possível perceber a partir do site VisiteFoz.

Essa construção se apropriou de duas dimensões distintas e, como aborda Souza, em determinados momentos rivais, mas com perspectivas não antagônicas, para construir seu discurso. Por um lado, as elites tradicionais de Foz do Iguaçu buscaram reivindicar uma memória que teria a vocação turística da cidade em seu centro, por outro lado, a Itaipu atuou no financiamento de pesquisas que narraram a história de Foz do Iguaçu a partir da ideia de harmonia social e cultural. Essas duas narrativas, - e aqui é o ponto em que buscamos avançar ao longo do texto - apesar de adversárias ao longo do processo de construção da Itaipu e de acomodação social dos interesses dessas elites, acabaram por se unificar, tentando tornar a harmonia cultural e a multiculturalidade em atrações turísticas da cidade. A própria Itaipu Binacional se tornou ponto de visitação, bem como, trabalhou na construção de outros pontos turísticos - Ecomuseu, Parque das 
Aves - e divulgação do turismo. Os anos 1990 consolidaram um processo de unificação dessas memórias a serviço do turismo.

Esse processo foi possibilitado a partir de dois momentos. Por um lado, a conclusão de Itaipu consolidou definitivamente sua presença na cidade, assim, a acomodação ou o confronto eram possibilidades colocadas pela situação para os dois conjuntos das elites locais. É nesse processo que o discurso de harmonia social e cultural permite pavimentar uma junção nos discursos em prol dos interesses comuns. Deste modo, a memória a serviço do mercado turístico amplia os atrativos locais das belezas da natureza agregando a harmonia e diversidade cultural, permitindo uma acomodação de ambas as perspectivas, satisfazendo os interesses da Binacional, em busca de apaziguamento social para a realização de suas atividades; os interesses das elites tradicionais, voltados para o financiamento das atividades turísticas e, finalmente, os interesses da elite tecnocrata de Itaipu que a partir da ideia de harmonia pode se inserir com maior tranquilidade na cidade. Não queremos com isso inferir nenhum novo tipo de harmonia social, dessa vez entre as elites de Foz do Iguaçu no tempo presente, apenas um trabalho de pesquisa aprofundado poderia analisar essa questão. O que afirmamos é uma acomodação no campo da memória que pode ter contribuído para uma acomodação de elites sociais diferentes.

Aliado a isso vemos o complexo processo de disputa de mercado no âmbito do turismo, onde diferentes cidades possuem e utilizam belezas naturais em busca de visitantes. Rio de Janeiro, Florianópolis, Angra dos Reis, as diversas cidades praieiras do Nordeste são destinos "clássicos" do turista em busca de belas paisagens. Foz do Iguaçu se localiza no interior do país, distante de outros roteiros turísticos. Sua disputa nesse mercado se deu, historicamente, pelas belezas das Cataratas. A presença de múltiplas etnias convivendo em "harmonia" pode ser, e tem sido, utilizada como um "diferencial" da cidade na venda de sua imagem para o potencial turista. Assim, produziu-se a ideia de que a cidade além de contar com belezas naturais, belezas artificiais - a barragem de Itaipu - contaria também, com uma multiculturalidade rica para ser conhecida.

Para finalizar gostaríamos de retomar a discussão que tem movido e permeado a narrativa que compõe esse texto. Temos argumentado constantemente que a narrativa oficial constrói um discurso de harmonia social na cidade de Foz do Iguaçu. Nas fontes apresentadas esse discurso é incorporado. A narrativa de harmonia social foi incorporada ao discurso da cidade, e compõe hoje um elemento importante de sua identidade 
propagandeada. Um momento de avanço nesse discurso poderia existir se a ideia de harmonia social - convivência não conflitiva entre diferentes - pudesse ser ampliada para integração, interculturalidade, enfim, relações que colocam os grupos em diálogo e relações de troca.

A narrativa da presença de múltiplas etnias enfatiza exatamente a presença delas. O próprio texto de Klauck e Szekut aponta como a construção do patrimônio cultural é fragmentada, onde cada grupo cultural produz "seu" patrimônio. A ênfase do discurso, como visto no início deste artigo, está na multiculturalidade, na multiplicidade étnica. $\mathrm{O}$ que vemos é um discurso muito mais próximo da construção, legitimação e positivação da ideia de "tribos urbanas" de Maffesoli (1987), do que da perspectiva política da categoria de interculturalidade apresentada por Canclini (2009).

A multiculturalidade e a interculturalidade não são excludentes, pelo contrário, a interculturalidade é entendida por nós enquanto um avanço político em relação à multiculturalidade. Comungamos da perspectiva de que não basta o reconhecimento da diversidade, da multiplicidade, faz-se necessário, para uma sociedade democrática, que essa diversidade entre em contato a partir de relações que se queira horizontais, mesmo que, por diferentes motivos se constituam verticalizadas.

Nesse sentido uma ênfase na interculturalidade poderia fazer emergir duas perspectivas e possibilidades. Enquanto categoria analítica, implicaria buscar compreender as relações entre os grupos culturais. Mais do que perceber e apontar sua existência e multiplicidade, interessa, para os fins sociais de um movimento intercultural, perceber se e como grupos culturais distintos se relacionam. Ao mesmo tempo, em nossa compreensão, o atual contexto social de avanços da xenofobia ao redor do mundo implica não apenas a coexistência de culturas, nem mesmo a existência orgânica de relações interculturais, mas uma política propositiva, por parte de diferentes agentes e setores públicos, de promoção da interculturalidade.

\section{Referências}

ARANHA, Renato Muchiuti. De Conjuntos habitacionais a bairros: A construção e o desmonte das vilas de Itaipu (1974-2012). Dissertação. UDESC, 2013.

BARBOSA, Marialva. Senhores da memória. Intercom - Revista Brasileira de Ciências da Comunicação, v. 18, n. 2, 1995. 
CANCLINI, Néstor García. Diferentes, Desiguais e Desconectados. $2^{\circ}$ Edição. Rio de Janeiro: Editora UFRJ, 2007.

Culturas Híbridas. São Paulo. EDUSP, 1997.

Imaginários Urbanos. Buenos Aires, Eudeba. 2010

CARVALHO, Francione Oliveira. Fronteiras Instáveis: Inautenticidade intercultural na escola de Foz do Iguaçu. Tese. Universidade Presbiteriana Mackenzie. 2011.

CATTA, Luiz Eduardo. A face da desordem: Pobreza e estratégias de sobrevivência em uma cidade de fronteira (Foz do Iguaçu, 1964-1992). Tese. Universidade Federal Fluminense - UFF. Niterói - UFF, 2005.

CERTEAU, Michel de. A Invenção do Cotidiano - Artes de fazer. Petrópolis: Ed. Vozes, 2014.

DOSSE, François. História do Tempo Presente e Historiografia. Tempo e Argumento, v. 4 n. 1.2012.

FREITAG, Liliane. Extremo-Oeste Paranaense: História territorial, região, identidade e (re)ocupação. Tese. Universidade Estadual Paulista - Unesp, Franca, SP. 2007.

GONZALEZ, Emilio. Memórias que narram a cidade: Experiências sociais na constituição urbana de Foz do Iguaçu. Dissertação. Pontifícia Universidade Católica PUCSP, São Paulo, SP, 2005.

HALL, Stuart. A questão multicultural. In: Da diáspora: identidades e mediações culturais. Belo Horizonte: Editora da UFMG/UNESCO, 2003.

Identidade Cultural e Diáspora. Revista do Patrimônio Histórico e Artístico Nacional, n.24, p.68-75, 1996.

KHOURY, Yara Aun. Muitas memórias, outras histórias: cultura e o sujeito na história. In: FENELON, Déa Ribeiro (Org.). Muitas memórias, outras histórias. São Paulo: Olho D’água, 2004.

KLAUCK, Samuel; SZEKUT, Andressa. Diversidade Populacional: Discursos de Fixação do Patrimônio Cultural de Foz do Iguaçu/Pr. Ideação. Vol. 14. N. 2. 2012.

KOSELLECK, Reinhart. Estratos do Tempo. Rio de Janeiro, RJ. Contraponto, 2014.

Futuro Passado: Contribuição à semântica dos tempos históricos. Rio de Janeiro, RJ. Contraponto, 2012.

MYSKIW, Antonio Marcos. A Fronteira como destino de viagem: A Colônia Militar de Foz do Iguaçu (1888-1907). Tese. Universidade Federal Fluminense - UFF, Niterói Rio de Janeiro. UFF. 2009.

OLIVEIRA, Nara Regina Olmedo de. Foz do Iguaçu Intercultural: Cotidiano e narrativas de alteridade. Dissertação. Universidade Estadual do Oeste do Paraná Unioeste, Marechal Cândido Rondon, Unioeste. 2012.

PASSERINI, Luisa. A Memória entre Política e Emoção. São Paulo: Letra e Voz, 2011.

POLLAK, Michel. Memória, Esquecimento, Silêncio. Estudos Históricos. Rio de Janeiro: CPDOC/FGV, vol. 2, nº. 3, 1989. 
Memória e Identidade social. Estudos Históricos, Rio de Janeiro, Vol. 5, n. 10, 1992. p. 200-212.

SOUZA, Aparecida Darc de. Formação econômica e social de Foz do Iguaçu: um estudo sobre as memórias constitutivas da cidade (1970-2008). Tese. Universidade de São Paulo - USP, São Paulo, SP. 2009.

STERLING, German Adolfo Ocampo. Representações Museográficas na Fronteira: Museo de la Tierra Guarani (Hernandárias/Paraguai) e Ecomuseu (Foz do Iguaçu/Brasil). Dissertação. Universidade Estadual do Oeste do Paraná - Unioeste, 2011.

\section{Fontes:}

Página sobre Foz do Iguaçu na Wikipédia:

https://pt.wikipedia.org/wiki/Foz_do_Igua\%C3\%A7u. Acesso em: 09/05/2016.

Site da Prefeitura Municipal de Foz do Iguaçu: http://www.pmfi.pr.gov.br/. Acesso em: 09/05/2016.

Site da Secretaria Municipal de Turismo de Foz do Iguaçu:

http://www.pmfi.pr.gov.br/turismo/. Acesso em: 09/05/2016.

Site Visite Foz: http://www.visitefoz.com.br/. Acesso em: 09/05/2016.

Recebido em: 17 de abril de 2017.

Aprovado em: 14 de junho de 2017. 